\title{
Across the waves: a bibliometric analysis of container shipping research since the 1960s
}

\author{
Yui-yip Lau ${ }^{\mathrm{a}, \mathrm{b}}$, César Ducruet $\quad$ c, Adolf K. Y. Ng ${ }^{\mathrm{b}, \mathrm{d}}$ and Xiaowen Fub,e \\ aDivision of Business, Hong Kong Community College, The Hong Kong Polytechnic University, Hong Kong, China; \\ ${ }^{\mathrm{b}}$ Transport Institute, Asper School of Business, University of Manitoba, Winnipeg, Canada; ${ }^{\circ}$ Centre National de la \\ Recherche Scientifique (CNRS and UMR 8504 Géographie-cités), Paris, France; 'Department of Supply Chain \\ Management, Asper School of Business, University of Manitoba, Winnipeg, Canada; Institute of Transport and \\ Logistics Studies, University of Sydney, Sydney, Australia
}

\begin{abstract}
The paper investigates collaborative and semantic patterns that emerged between 1967 and 2013 about the theme of container shipping based on a corpus of 294 articles published in scholarly journals within the fields of transportation, supply chain, economics, geography, regional planning and development, and operations research. An analysis based on the cooccurrence of title words allows identifying dominant sub-themes and their evolution. Main results point to the gradual diversification of container shipping research, from the dominance of economics towards a more trans-disciplinary set of approaches which integrate port-related activities and multimodal networks. Yet, disciplinary specialization remains strong up to nowadays so that container shipping research remains rather fragmented. While co-authorships have increased over time, they remain polarized by few, weakly connected research battalions. Our study suggests that research on container shipping would benefit from more frequent contacts between such communities to foster in-depth crossdisciplinary studies and fundamental cooperation.
\end{abstract}

\section{KEYWORDS}

Co-occurrence network; collaboration network; container shipping; research trends; semantics analysis

\section{This is the draft version of the article published in Maritime Policy and Management, Vol. 44, No. 6, pp. 667-684}

\section{Introduction}

In the maritime industry, container shipping has been carrying cargoes in different parts of the world as a backbone of international trade development (Du, Meng, and Wang 2017; Ducruet 2017). Container shipping had undergone substantial transformation and breakthrough development in the last century, notably containerization, substantial growth in international trade, technological innovation, and the integration of ships and ports into logistics and supply chains (Ng and Liu 2014). Container port traffic has dramatically increased from 224,774,536 TEUs in 2000 to $679,264,658$ TEUs in 2014 (Containerization International Yearbook, 2016), while global containerized trade reached 171 million TEUs in 2014 (UNCTAD 2015). Container shipping had contributed over $80 \%$ of international trade volumes and more than $70 \%$ by value in 2015 (Shi and Li 2017). The industry growth has been accompanied with changes in technologies, operations, economics, and regulations. The average containership size in the global fleet increased at a 
cumulative annual growth rate of $18.2 \%$ between 2010 and 2015 (UNCTAD 2015). Although container ships accounted for $4 \%$ of all vessels, they accounted for $20 \%$ of emissions from international shipping in 2007 (Psaraftis and Kontovas 2009). Emission control and environment-related issues are of increasing concerns to the international community (IMO 2000, 2009; Homsombat et al. 2013; Wang, Fu, and Luo 2015). Port operations involve more and more stakeholders (De Langen 2007; Lam, Ng, and Fu 2013) and have far-reaching effects on their regions and hinterlands (Wang 1998; Notteboom 2009; Ferrari, Parola, and Gattorna 2011; Homsombat, $\mathrm{Ng}$, and $\mathrm{Fu}$ 2016). All these dynamics and emerging challenges have led to a significant increase in research works addressing different aspects of the maritime sector, as discussed in Pallis et al. (2011), Woo et al. (2011), Ng (2013), Lau et al. (2013) Notteboom et al. (2013), and Ng and Ducruet (2014). Despite such abundance, few studies systematically investigate the nature and structure of the research communities, especially on the container shipping side. This is not to say that no efforts have been done to address the problem-like the special issue commemorating four decades of maritime research by Maritime Policy \& Management (MPM) in celebrating the journal's 40th anniversary (edited by Wilson 2013, volume 40, issue 7). Talley (2013) reviewed and analysed maritime transportation academic research by investigating the most frequent topics and methodologies used. Such an investigation led to rich insights, with some important research areas identified. However, only MPM and Maritime Economics and Logistics were included in the analysis of maritime studies. Lau et al. (2013) analysed the evolution and research trends of container shipping by categorizing relevant studies into different approaches, namely economics (e.g. demand, supply, and pricing), management (e.g. seafarers and organizational governance), and operations (e.g. turnaround time, vessel size, route schedule design problem).

Like what was often described by historians, review studies must achieve 'social construction' (see Berger and Luckmann 1966) for the research communities concerned that emphasized on the historical value, the lessons learnt, and the ethical judgments of past events. In shipping and port research, an illustrative example of review work aiming at social construction could be found in $\mathrm{Ng}$ and Ducruet (2014) - their investigation on the nature and structure of port geography research extended their earlier content analysis study on the evolution and research trends of this corpus (i.e. Ng 2013) beyond the 'story telling' phase, identifying the strengths, shortcomings, challenges, and the changing relationship between port geography and its mother disciplines, namely human and transport geographies. To some extent, $\mathrm{Ng}$ et al. (2014) inspired other port geography researchers to seriously re-evaluate the fundamental philosophy and epistemology of port geography and port geography research-such as the initiative in organizing a special session on port geography during the Annual Conference of the Royal Geographical Society (in collaboration with the Institute of British Geographers) (RGS-IBG) in 2014 (RGS-IBG 2014).

Recognizing such criticality, this paper undertakes a systematic analysis on the structure of a container shipping research corpus made of 294 journal papers published by maritime researchers between 1967 and 2013. By nature, containerization has revolutionized maritime transport, port operations, offshore support industry, and intermodal transport system across all boundaries, thereby constantly bringing new questions to the research community, and forcing scholars to step out of their traditional modal and local/regional nest. Here, we seek to find new and relevant information that characterizes the container shipping corpus and its evolution. Network analysis appears to be a relevant approach, not only methodological but also conceptual, to measure and visualize the structure of a corpus (Newman 2010). Two methods are mobilized to achieve such a goal: the analysis of collaborations (co-authorships) and the one of semantics or word co-occurrences. The focus on co-authorship is a highly relevant first step to understand the structure of the research community, understanding that the substantial increase in collaboration was a trend of characterizing contemporary research in the past two decades. Similar to Ng and Ducruet (2014), this study continues the work done by Lau et al. (2013), with a view to socially construct the past, present, and future value of container shipping research. Through these methods, we identify the evolving pattern of collaboration among researchers, the core topics addressed, and how they have been interlinked overtime. They allow us to explore missing links and research trends, thereby 
identify emerging areas of innovation and further enhance effective cooperation in the research community.

The rest of the paper is structured as follows. Section 2 explains the methodology and data utilized. This is followed by the illustration of investigation findings and result interpretations in Section 3. Finally, the conclusion can be found in Section 4.

\section{Methodology}

\subsection{Elaboration of a corpus on container shipping}

Acorpus was first compiled through a comprehensive review on the research papers related to container shipping published in internationally recognized scholarly journals. Because relevant studies have been carried out in multiple disciplines, focusing on 'transport' or 'maritime' journals only will miss out important articles. Therefore, the following procedure was used to compile an article database: we started with title and keyword searches on the journals in the transport discipline as listed in the Science Citation Index (SCI) report. We then went through the references in the searched papers to locate more relevant studies, which appeared in a total of 31 scholarly journals in the maritime, transportation, applied economics, geography, and operational research disciplines. To leverage on the insights obtained in the earlier review by Lau et al. (2013) and to maintain consistency and continuity in research, we have built our database on that used in Lau et al. (2013) and further expanded our database in Appendix 2. Keyword and title searches were carried out again for container shipping within these journals, resulting a total of 294 papers (co-)authored by 231 authors, addressing various aspects of container shipping. We focused on articles published between 1967 and 2013, for which we had access to electronic journals. To some extent, the resultant article database may be regarded a sample of convenience. Nevertheless, such representative large sample covering publications over almost half a century allows us to capture relevant studies in multiple disciplines so that we could identify the changing patterns and themes of container shipping study, and how these patterns and themes have evolved over time. For this purpose, we divided the study period evenly into three 'sub-periods' (1967-1982, 1983-1998, and 1999-2013) representing the 'classical,' 'interim,' and the 'contemporary' ages in container shipping research. Each period is long enough to characterize the significant changes in the industry (e.g. the rise of mega-sized container ships, merger, acquisitions, and the establishment of strategic shipping alliances, the increasingly explicit establishment of maritime logistics and global supply chains). On the other hand, the divisions of periods allow us to identify the shifting patterns over time so that to get insight into the driving forces behind such changes. Such a periodization well corresponds to the different 'waves of containerization' across ports of the world, defined by Guerrero and Rodrigue (2014) as the pioneers, early adopters and diffusion waves (1970s to mid-1980s), the acceleration and standard waves (mid-1980s to late 1990s), and the peak and niche waves (early to late 2000s). Maritime shipping in the past several decades was characterized by the increasingly popular use of containers for most general cargoes and even oversized cargoes (Pelletier and Alix 2004; Ng 2006; UNCTAD 2014). A thorough understanding on the nature and structure of the container shipping research community will bring important insight into the understanding of maritime studies in general.

The list of journals, together with respective disciplines, can be found in Table 1. The list of papers is not reported due to page limitation but is available upon request.

\subsection{Co-authorships}

The bibliometric approach applied to the sample first rests on collaborative (co-authorship) analysis within and between papers using social network analysis techniques, and the investigation results are illustrated using the TULIP graph visualization software. ${ }^{1}$ It should be noted that research collaborations were analysed on the basis of the authors having written together some of 
Table 1. The scholarly journals which have published papers related to container shipping between 1967 and 2013 and their affiliated academic disciplines.

\begin{tabular}{lc}
\hline Title & Discipline \\
\hline Applied Economics & ECN \\
European Journal of Transport and Infrastructure Research & TRL \\
Growth and Change & GPD \\
Geoforum & GPD \\
GeoJournal & GPD \\
International Journal of Logistics: Research and Applications & TRL \\
International Journal of Logistics Systems and Management & TRL \\
International Journal of Ocean Systems Management & MAR \\
International Journal of Physical Distribution and Logistics Management & $\mathrm{TRL}$ \\
International Journal of Shipping and Transport Logistics & $\mathrm{TRL}$ \\
International Journal of Sustainable Transportation & $\mathrm{TRL}$ \\
Journal of Business Logistics & $\mathrm{TRL}$ \\
Journal of the Operational Research Society & $\mathrm{OPR}$ \\
Journal of Transport Economics and Policy & $\mathrm{ECN}$ \\
Journal of Transport Geography & $\mathrm{GPD}$ \\
Marine Policy & $\mathrm{MAP}$ \\
Maritime Economics \& Logistics & $\mathrm{MAR}$ \\
Maritime Policy \& Management & $\mathrm{MAR}$ \\
The Review of Network Economics & $\mathrm{ECN}$ \\
Research in Transportation Economics & $\mathrm{TRL}$ \\
Review of Urban and Regional Development & $\mathrm{GPD}$ \\
Transportation Research Part A: Policy and Practice & $\mathrm{TRL}$ \\
Transportation Research Part B: Methodological & $\mathrm{OPR}$ \\
Transportation Research Part C: Emerging Technologies & $\mathrm{TRL}$ \\
Transportation Research Part D: Transport and the Environment & $\mathrm{TRL}$ \\
Transportation Research Part E: Logistics and Transportation Review & $\mathrm{TRL}$ \\
Transportation Journal & $\mathrm{TRL}$ \\
Transport Policy & $\mathrm{TRL}$ \\
Transport Reviews & $\mathrm{TRL}$ \\
WMU Journal of Maritime Affairs & $\mathrm{MAR}$ \\
World Development & $\mathrm{GPD}$ \\
\hline ECN Economics & \\
\hline
\end{tabular}

ECN: Economics (including transport journals with a clear 'economic' taste); GPD: Geography, Planning, and Development; MAR: Maritime; OPR: Operations Research and Operations Management; TRL: Transport and Logistics.

MPM was preceded by Maritime Studies and Management on and before 1976.

MEL was preceded by the International Journal of Maritime Economics on and before 2003.

Source: Authors.

the articles, which allowed for measuring the rate of single-authored papers and representing the network of co-authors at different periods so as to verify the underlying community structure.

The network analysis of scientific collaborations is often applied to large corpuses of publications so as to extract meaningful information about the existence of communities (clusters) of different kinds in such a network and identify their factors of emergence, for example, geographic, linguistic, and/or disciplinary proximity, etc. (Newman 2004), as well as to identify the overall structure of the collaboration pattern, from fragmentation to cohesion (Newman 2010). In this study, the analysis of collaborations follows a straightforward approach that is to consider in a graph nodes (vertices) as authors and links (edges) as a co-occurrence of two authors in the same paper. All authors of the same paper are considered connected regardless of the order of authors and regardless also of their specific role such as corresponding, etc. It should be emphasized that such an analysis captures the linkages among researchers. A highly productive researcher will not be well identified if he/she did solo work only or work with a small group of co-authors consistently over time.

\subsection{Semantics}

The analysis of semantics falls into the area of co-occurrence network analysis whereby scholars search for the emergence of ideas and trends in large corpuses (Knuth 1993; Ferrer, Cancho, and 
Sole 2001). Several options have been utilized in the literature. Depending on the desired level of precision and exhaustiveness, the analysis can apply to entire texts or to the abstract, keywords, title words of the corpus articles. The analysis of entire texts is preferable when, for instance, the goal is to extract meaningful word patterns in order to identify the true author of a manuscript or to detect plagiarism. Instead, this study limits itself to the analysis of title words. One first reason is that not all articles contained abstracts or even keywords over the study period, especially before the 1990s. Second, title words best summarize the main topics of papers in most cases because they represent the first information viewed by the readers before they reach the rest of respective works. In addition, our motivation using title contents comes from parent approaches in different areas such as medical science, where it was proven, for instance, that title length and construction were highly correlated with the number of citations (Jacques and Sebire 2010). Similar quantitative investigations based on sole title words can be found throughout the literature on semantics and cognitive landscapes (see Lewison and Hartley 2005; Milojević et al. 2011). Such works argue that title words carry and condense the most powerful information of articles, notwithstanding certain methodological issues in terms of data preparation, as explained further in the following sections.

\subsubsection{Definition and selection of words and expressions}

The analysis of title words involved an important phase of data preparation. One first step was to identify important words and expressions. Getting inspiration from the work by de Bakker, Groenewegen and Den Hond (2005) who analysed a 30-year corpus of publications in another research field based on title words, our method consisted in removing the most common words from the titles such as prepositions (e.g. and, the, of, etc.) and to focus, among the remaining ones, on the most relevant words and expressions. The exclusion was motivated by the fact that certain words did not carry sufficient meaning per se, such as 'transport,' 'structure,' and 'development.' Whenever possible, such words were adapted through a thesaurus operation such as 'transport cost' changed to 'shipping cost,' so as to keep the original meaning and allow better comparability across the corpus and over time, as these two expressions were used indifferently by a number of articles. Another illustrative example is 'shipping line' that covers 'shipping firm,' 'shipping company,' 'shipping industry,' 'ship operator,' and 'ocean carrier.' The variability of words to name and describe basically the same object needed careful harmonization in order to avoid splitting knowledge. Some were relatively easy to address, such as 'container ship' covering 'container vessel,' 'cargo liner,' 'containership,' and 'vehicle.' Others represented difficult choices to make. One example is the geographical area under study (i.e. country, range, sea or ocean, and sometimes a line such as Europe-Asia) that was harmonized at the level of continents to better detect certain trends in the geographic or even cultural specialization of container shipping research (i.e. Asia, Europe, North America, Latin America, Africa, and Oceania). A category of 'developing countries,' however, was kept as it was often used in past decades without further notice on which exact area was studied, as well as 'North Atlantic' and also 'global' (including 'world').

In addition, considering title words in a strict individualistic manner would have made little sense for a number of reasons, since 'freight' for example may be a noun or an adjective, and in the latter case, combined with totally different nouns, such as 'freight transport,' 'freight integration,' and 'freight cost.' The same applied to the word 'system' that combines to provide 'transport system,' 'conference system,' 'tariff system,' and 'port system.' Certain words and expressions were constructed to produce a more compact thesaurus, but without being always named as such 'container management' covers issues related with container allocation and repositioning for instance, 'fleet management' includes fleet deployment and fleet planning, 'network design' assembles various but similar aspects of 'service design,' 'network efficiency,' 'network modelling,' 'optimal route design.' This choice does not avoid keeping, as in the last example, 'route,' 'efficiency,' 'routing,' and 'optimal' as individual words because they express particular objects and approaches that also have links with other aspects than 'network design.' 
With the above data preparation, the construction of the related networks was based on the cooccurrence of words and expressions within the same article title. Nodes in the network are thus words and expressions, and the links between them are defined by their co-occurrence. In other words, words and expressions linked with each other if they appear within the title of the same journal article. Each network is thus an adjacency matrix made of such nodes and links, on the level of three consecutive periods: 1967-1982, 1983-1998, and 1999-2013. Such networks are weighted according to the frequency of the appearance of nodes and links in the corpus and within each period. Nevertheless, additional data preparation was necessary before analysing these networks.

According to Zaidi (2011), such co-occurrence networks in the case of novels, books, professional magazines, and the World Wide Web can also be defined by the appearance of words in the same paragraph or page, at the condition that the most frequent and obvious words should be deleted, in order to reveal hidden structures. Three words and expressions were thus excluded based on such criteria: shipping line, container ship, and containerization. Given the specific nature of the selected corpus, these three elements appear in most article titles. The sub-themes within container shipping research and their interrelationships are generated in a higher level of significance. Indeed, 'shipping line' and 'container ship' have the highest frequency among all words and expressions, with 62 and 33 occurrences, respectively, but 'containerization' is only at the 21 st rank with 15 occurrences, over the whole period.

\subsubsection{Delineation of semantic categories and preliminary results}

Another important aspect was to assign a semantic category to each of the aforementioned words and expressions. This step was judged necessary in order to start the verification of the hypotheses at a higher level of analysis. In other words, have specific semantic areas within container shipping research been jointly or individually represented in article titles? Is there a trend towards specialization or diversification? For such purposes, seven categories were sufficient to encapsulate all the words and expressions contained in the corpus under study (Table 2.). ${ }^{2}$ Each category has a relatively balanced number of words/expressions.

One first result based on such categories was obtained by calculating the share (\%) of intraversus inter-category occurrences by main period. While this share is a good indicator of semantic diversification in the case of a decrease, it has actually increased from 16.9 to 17.9 and 21.9 from one period to the other. This means that there has been a slight but continuous tendency for container shipping research papers to become increasingly specialized within a specific semantic field. Figure 1 provides more clues about the co-occurrences among the different categories and their shift over time. We see that 'economics' and 'operations management' dominate the first period by the diversity of their links to other themes as well as by their strong mutual frequency. In the second period, the link between 'areas and markets' and 'ports and shipping routes' became the strongest, while the link between 'economics' and 'operations management' has almost disappeared. But the major change is the increasing frequency of 'ports and shipping routes' with most other themes, especially with 'operations management' that has become the largest link. Perhaps, improved quantitative techniques have favoured a renewal of measures and methods,

Table 2. Categorization of title words and expressions.

\begin{tabular}{llc}
\hline Semantic field & \multicolumn{1}{c}{ Rationale } & No. of words \\
\hline Areas and markets & Location, scale, regions, and countries & 13 \\
Economic analysis & Costs, rates, prices, and measures & 12 \\
Intermodal chain & Land-sea, modes, and actors & 12 \\
Issues, outcomes, and objectives & Constraints and improvements & 21 \\
Management, behaviour, and policies & Shipping industry & 22 \\
Operations management & Organization and planning of flows & 16 \\
Ports and shipping routes & Distribution of nodes, routes, and flows & 16 \\
\hline
\end{tabular}

Source: Authors. 


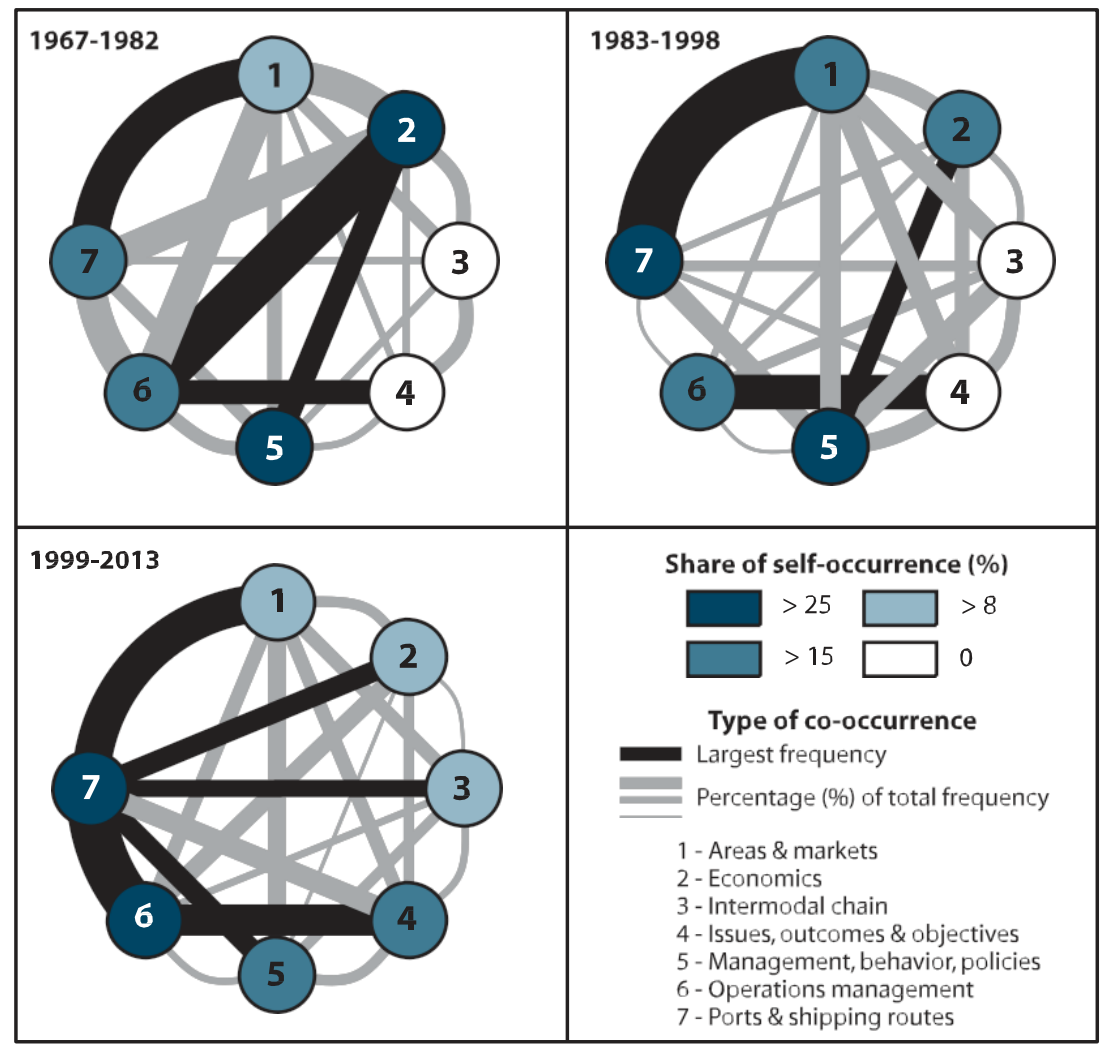

Figure 1. Categorization of title words and expressions.

Source: Authors.

while container shipping has been increasingly related with port activities and their connectivity. A similar pattern can be observed for 'management, behaviour, and policy,' which lost its strong linkage to 'economics' over time. It is important to note that the most connected themes are also the most self-occurring; in other words, the dominant and most interactive themes are also the ones being able to specialize. This allows moderating the aforementioned trend of specialization versus diversification, as both evolutions go together. Emerging fields increasingly embed with others while reinforcing their own approach to container shipping.

\section{Investigation results and discussions}

\subsection{Scientific collaborations}

Based on the stated methodology, Figure 2 illustrates co-authorships between 1967 and 2013.

Figure 2 revealed the emergence of well-connected communities of researchers in the third period only, while the first two periods comprised papers being either single-authored for a majority of them, or papers without common authors. This means that in 1967-1982 and in 1983-1998, research on container shipping remained extremely fragmented among scattered groups of researchers having little mutual relations, at least formally, despite the potential proximity of their respective topics and interests. In fact, during these two periods, collaboration was the exception rather than the rule. Having said that, still, some embryonic, sporadic development of collaboration could be found in the second period. 


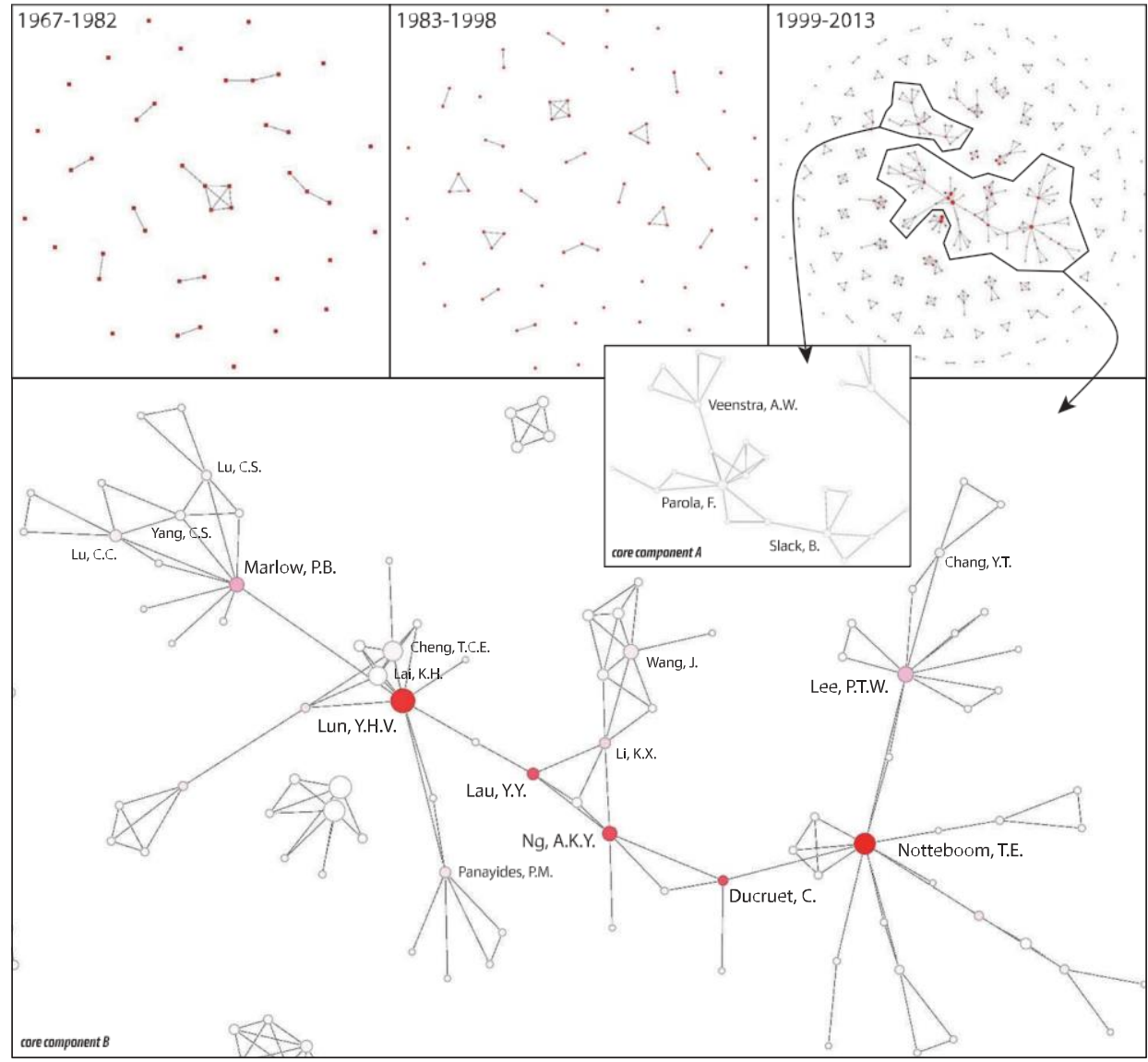

Figure 2. Graph illustrating co-authorships across container shipping research, 1967-2013.

Source: Own realization based on TULIP software.

In the third period (1999-2013), certain collaborative 'trunk lines' gradually emerged, which largely involved Western European and East Asian researchers. Such an evolution towards more connectivity in the 1999-2013 period is not specific to container shipping research and is certainly promoted by rapid progresses in telecommunications and people's mobility in the academic world (especially, with the fast development of international conferences, global networks of scholars, etc.). Nevertheless, the connectivity process had not been uniform, which led to the formation of two distinct 'core components' that go beyond the sole individual papers and authors. This growing connectivity should not, however, be over-exaggerated because the internal structure of components ' $\mathrm{A}$ ' and ' $\mathrm{B}$ ' is closer to a 'chain' pattern, with a linear alignment of 'weak ties' (Granovetter 1973) connecting dense subgroups around one or two researchers. In the 'A' component, few transversal linkages exist between the subgroups centralized by Parola, Slack, and Veenstra. It reflects more the ability of a few researchers to deploy large-scale collaborations without which the overall pattern would still resemble the former periods. The same applies to the 'B' component, where Notteboom, Lee, Lun, and Marlow are very much central and also among their direct neighbours. These subgroups are connected also via certain 'brokers,' such as $\mathrm{Lau}, \mathrm{Ng}$, and Ducruet that have considerable collaborations in volume. The academia is somewhat strategically located between densely connected subgroups, mainly due to their diverse research portfolios instead of a specialization into one main research arena only. Indeed, the densely connected 
subgroups reflect certain logic in terms of disciplinary belonging (e.g. transport geography, operations research) but without strict delineations. Collaboration in the field is thus still fragmented in some way, as the main communities depend on a few links to connect to each other, and a few researchers having multiple international collaborations.

When looking into the 'trunk line' more closely, we found that the container shipping research community possessed certain 'blocks.' As stated earlier, although the 'trunk line' was developing a 'chain' pattern, the connections between the 'central components' (Lun, Lee, Marlow and Notteboom) and 'brokers' (Lau, $\mathrm{Ng}$ and Ducruet) were, in fact, rather weak. Many of the 'central components' seemed to have established a somewhat 'closed' system, of which collaboration largely existed among proximate colleagues based on various factors (e.g. the same department, cultural similarities). For instance, as shown in Figure 2, Lun had established strongly bounded cooperation with colleagues within the same department and university (notably Cheng and Lai, and to some extent, Lau, at the Department of Logistics and Maritime Studies of the Hong Kong Polytechnic University). Of course, colleagues in the same department or university, including $\mathrm{PhD}$ students and their supervisors, often have a higher chance of cooperation, as manifested by other examples such as $\mathrm{Lau}, \mathrm{Ng}$, and $\mathrm{Li}$ (former colleagues in the Hong Kong Polytechnic University), as well as between Lu and Marlow (PhD graduate and supervisor at the University of Cardiff).

These observations offer a mixed message to the research community on shipping and probably to maritime studies in general: on the one hand, such a pattern suggests that intensive interactions, occasionally facilitated by physical proximity, do lead to cross-fertilization and research cooperation. Therefore, $\mathrm{PhD}$ graduation and job relocation will 'naturally' increase the chances of cooperation among researchers over time. As shown in Figure 2, in period 3, it was not difficult to identify the establishment of many similar but isolated 'research battalions' in addition to the major blocks identified earlier, indicating a general increase of co-authorship compared to previous periods. On the other hand, this suggests that whereas seminars, workshops, conferences, improvements in mobility, and sophisticated computer technology did facilitate frequent communication among researchers, probably, they are yet to play sufficient roles in fostering research cooperation across continents. The rise of small, local/regional 'research battalions,' in some cases within the same school/ department, implied that collaboration was perhaps not as 'international' and 'external' as initially thought. Indeed, our earlier work (i.e. Lau et al. 2013) highlighted the highly 'skewed' collaboration in container shipping research, in which scholars affiliated to institutions located in the world's economic powerhouses (East Asia, Western Europe, and North America) largely dominated container shipping research during the past five decades. The concentration of collaboration within these 'research battalions' indicated that one of the most important added values of collaboration, namely the combination of knowledge and experiences from different places and cultures, might not have achieved its full potential. The importance of distance (despite modern information and advanced communication technologies) was also demonstrated by the work of Pan, Kaski, and Fortunato (2012) who analysed worldwide citations and collaboration networks based on the entire ISI Web of Science. This would not do any favour to the development and well-being of shipping and maritime research. Therefore, the maritime community probably should endeavour to provide opportunities of extensive interactions, such as sabbatical visits among established researchers, extensive and focused research workshops, higher education forum, and training summer camps for young researchers and graduate students. In addition, although our study investigating a corpus covering a wide range of research disciplines, cooperation has mostly been found in the fields of management and economics, with geography and network analysis studies connecting different groups. Thus, as mentioned, the cooperation in the container research community is not as extensive as expected and cross-disciplinary studies are yet to be fully developed. 


\subsection{Semantic analysis}

In the first period (1967-1982), the graph of co-occurrences is, interestingly, composed of two main components (or subgraphs) with no links between them as well as four pairs of words standing apart (Figure 3). As confirmed in Appendix 1 presenting the frequency of title words by period, the first period is marked by a dominant economic approach as seen with the paramount importance of pricing, freight rate, and economics for instance. This reflects the fact that the key research topics during this period were related to shipping conference and regulatory issues, market equilibrium, freight rate and demand (Lau et al. 2013). Yet, the existence of two components reveals a fragmentation of container shipping research in terms of its dominant approaches. One component, centred upon 'North America' because a majority of applications relate to this region, concerns mostly the more operational or econometric approaches to shipping routes in relation to freight rates and tariffs. Yet, cost and price considerations are included in the second component (including Europe and Asia), alongside the operational (time, size) and managerial (conference, competition) aspects of container shipping. The main difference between the two components is that the more practical dimension of container shipping is included in the second, with regard to the presence of 'optimal,' but also fuel and speed. The peripheral position and connexion of 'geographic' and 'global' are emblematic of the dominant economic contents of container shipping research in the early phase, which mostly concentrated on measuring costs and describing operations in the industry regardless of its spatial embedding. Themes that by nature are not in the core of container shipping research are also relegated to the periphery, such as 'shipper' and 'decision-making,' which are more qualitative in scope as they suggest taking distance from the 'pure' transport actors and their daily operations.

In the second period (1983-1998), the graph is much better connected, but it is still possible to detect certain preferential connexions internally (Figure 4). One first difference

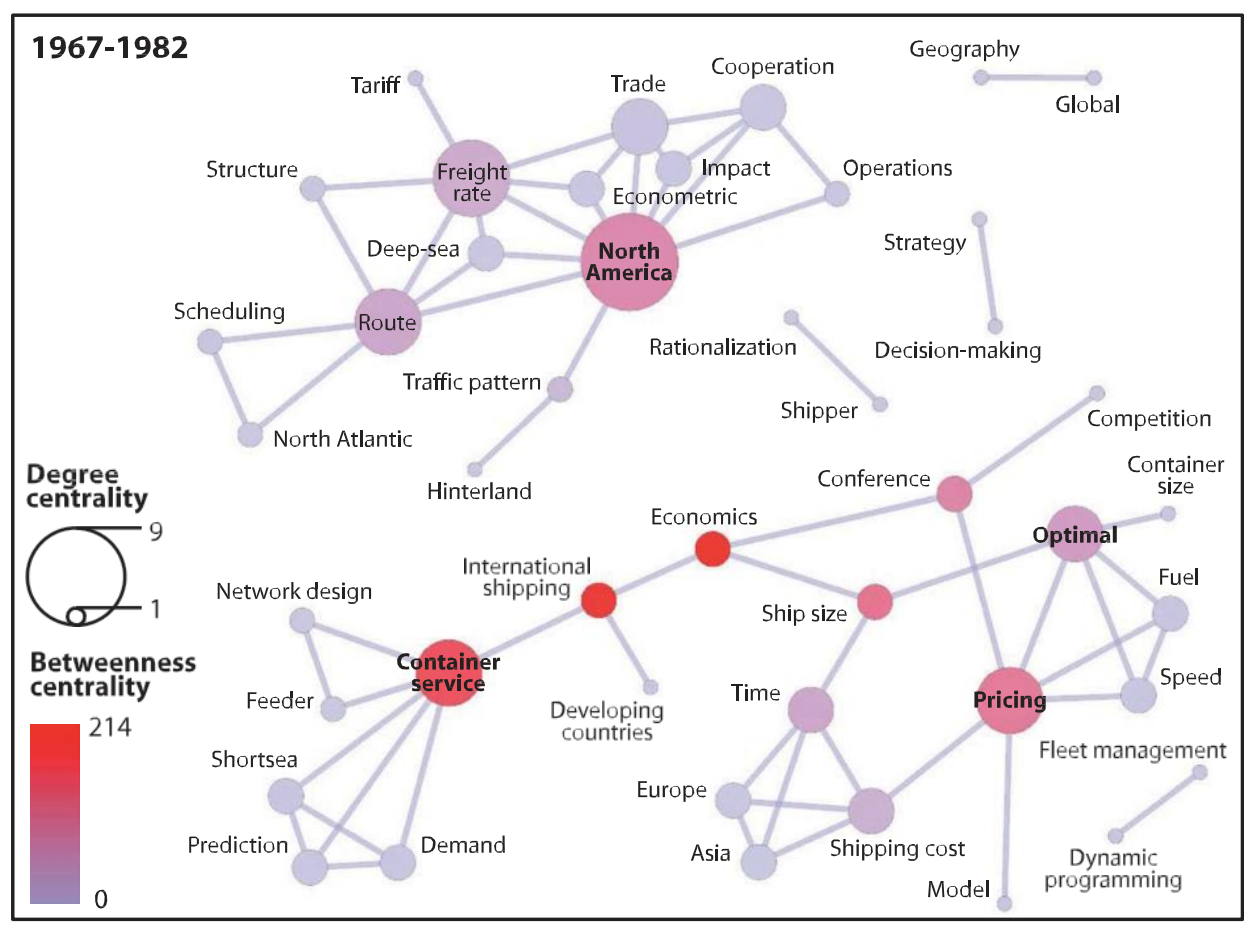

Figure 3. Co-occurrence graph of title words, 1967-1982.

Source: Own realization based on TULIP software. 


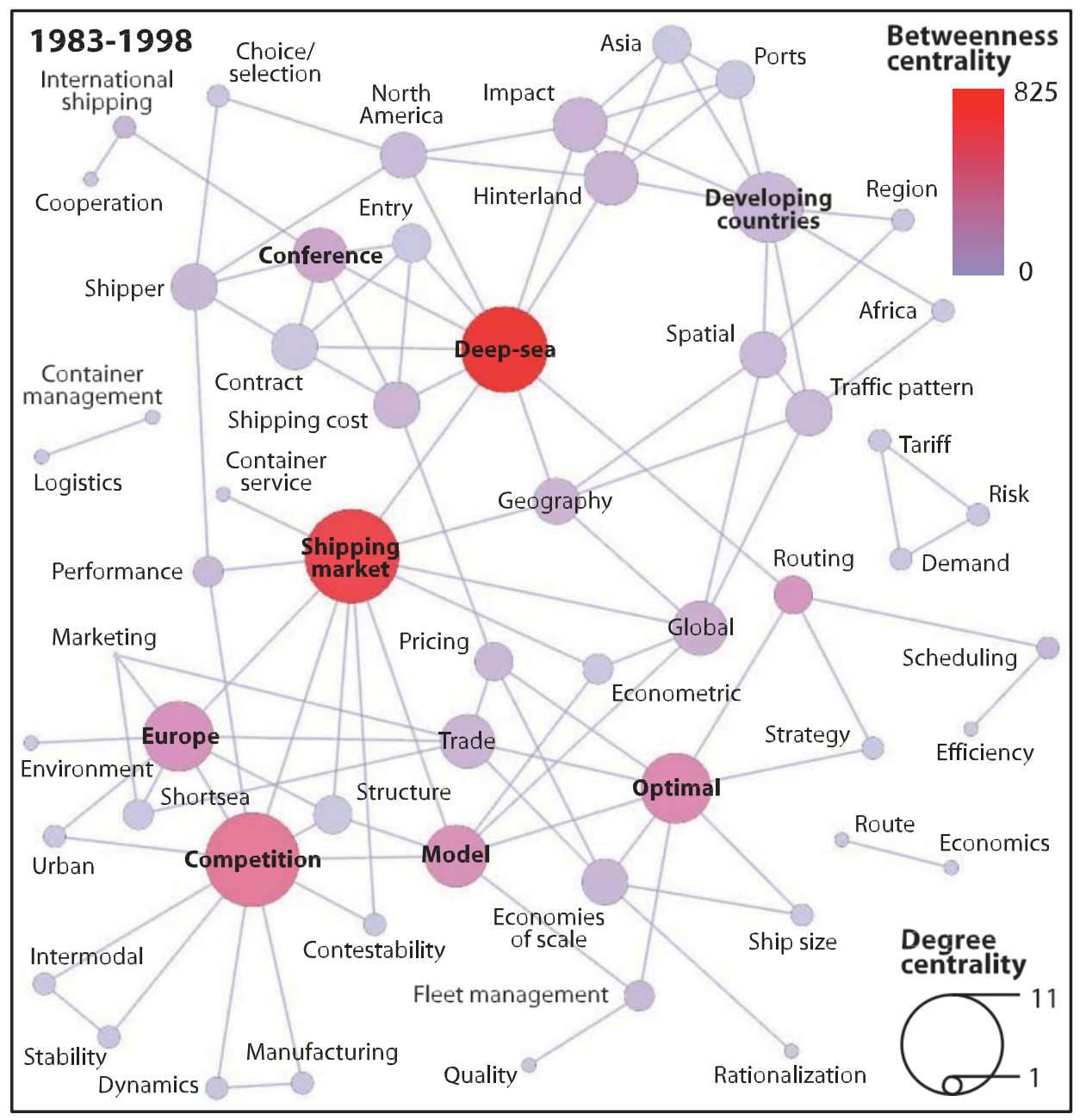

Figure 4. Co-occurrence graph of title words, 1983-1998.

Source: Own realization based on TULIP software.

with the previous period is the decline of 'North America' and the growth of 'Europe' as main topics and study areas. One likely reason is the increasing number of European scholars developing studies on container shipping, in a context of increased port competition and intermodal transport in Europe itself. Second, one important change is the shift of 'geographic' and 'global' from the periphery in the previous period to the core in the second period, partly due to a more active engagement of transport geographers in container shipping research (Ng and Ducruet 2014), as confirmed by the equivalent presence of 'region,' 'spatial,' 'scale,' and 'hinterland,' which are fundamental concepts throughout human (and port/maritime) geography in general. In addition, those geographical concepts happen to connect much with each other while most of them are associated with 'developing countries' (but also Asia and Africa). Such a trend reflected the shift from a Western-based, core-periphery world economic system to a more polycentric one, as well as the growing need to understand the diversity of local responses to the global spread of containerization through successive diffusion waves (Guerrero and Rodrigue 2014), while Europe had a specific character based on the importance of short-sea shipping, to which it is strongly connected in the graph. 
Another interesting aspect of the second period is that formerly central themes have become peripheral, such as 'route,' 'economics,' 'container service,' 'international shipping,' and 'tariff,' while others have strengthened their position, such as 'optimal,' 'shipper,' 'model,' 'deep-sea,' and 'competition.' This underlines a shift from economics to management, in relation with drastic evolution of the container shipping industry, notably in the 1990 s when container carriers started to horizontally and vertically integrate within global transport and value chains (see Robinson 2002). All these have led to the formation of supply chains and container shipping operations at regional/global levels, which attracted academic studies in the related fields. Still, some emerging concepts in container shipping research, such as 'logistics,' 'intermodal,' 'choice/selection,' 'safety,' and 'environment' for instance remain rather peripheral.

In the third period (1999-2013), because of the graph's larger size (in terms of the number of nodes and links) and higher density, ${ }^{3}$ two distinct methods of graph simplification and partitioning were applied. Single linkage analysis (SLA) keeps only for each node its largest link to another node based on frequency weight, thus transforming the network into a tree graph split into several connected components (Nystuen and Dacey 1961). This allows us to examine which words/ themes have dominated container shipping research and how such dominance has changed overtime. The second method, bisecting k-means, is less concerned about hierarchical structures. Instead of removing many links as in the previous method, it partitions the graph into subcomponents based on their internal density of links (Savaresi and Boley 2004).

As seen in Figure 5, important shifts occurred towards new central words. 'Ports' and 'network design' are among the most central elements of the third period. The emergence of 'network design' in particular has much to do with the growing integration of the 'network' concept in shipping and logistics studies in general (Ducruet and Lugo 2013) where the shape and architecture of container flows has become a core question as much as the operational and economic aspects. The analysis of shipping flows benefited from both the application of graph theory and

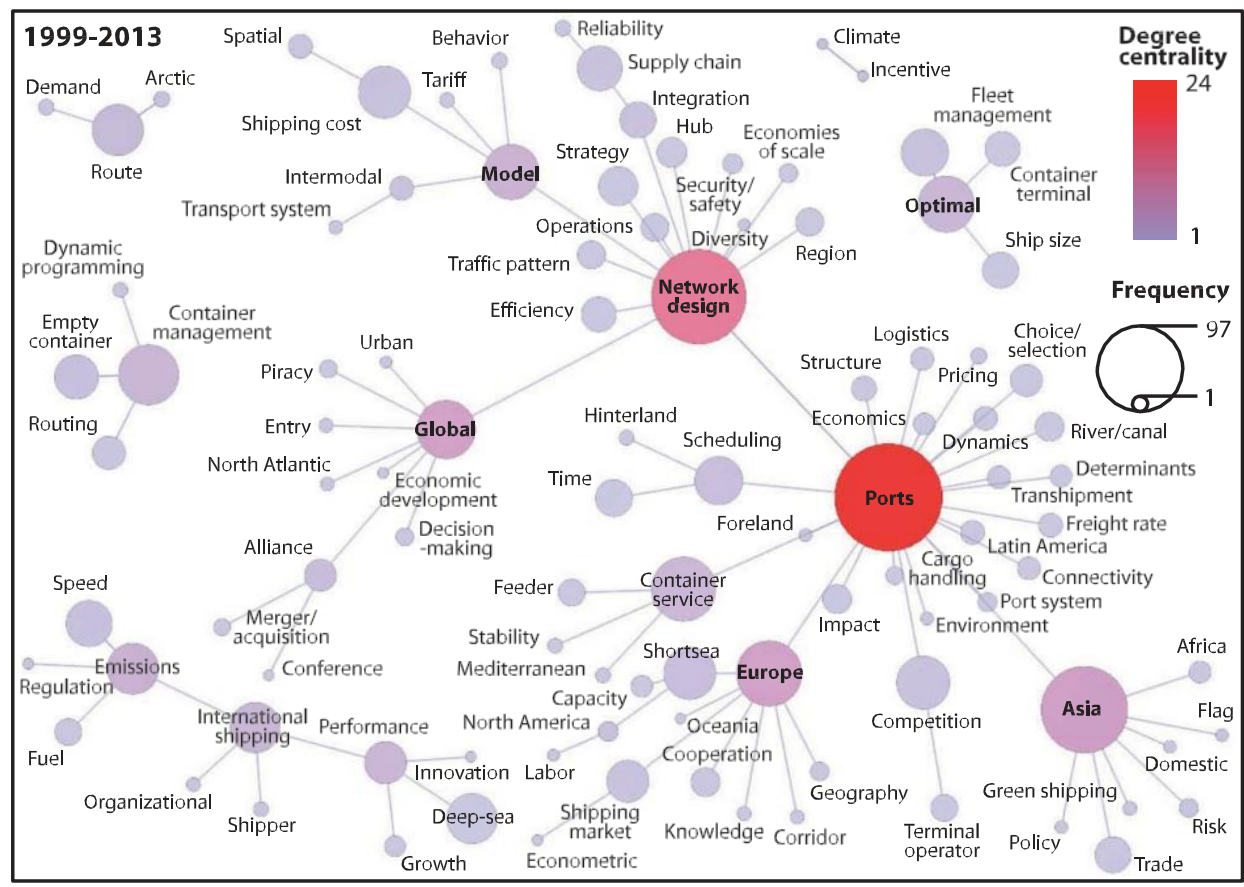

Figure 5. Single linkage analysis of title words, 1999-2013.

Source: Own realization based on TULIP software. 
the growing availability of large-scale data sets. For instance, complex networks measures were applied to the various maritime networks of which container shipping based on the intensity of inter-port vessel movements (Ducruet 2015). The importance of 'ports' is also explained by more emphasis put on the integration of transport and logistics chains, and the involvement of ocean carriers into dedicated terminal operations (Slack and Frémont, 2005), as shipping activity and port activity could no longer be analysed individually but rather, as part of one single reality. By contrast, classic and formerly central themes such as 'optimal' became peripheral, as in the recent period, such approaches got strongly related to operations research, which tends to get isolated from economic and management studies. Certain themes remain apart the central 'backbone,' for instance groups of words related with not only routing, programming, and containers, but also environmental issues (emissions, speed, fuel, and climate). In terms of geographic dominance, the third period is very much emblematic of the new central role of Asia in the shipping business and related research, followed not only by Europe but also by 'global.'

When looking at the same period from another perspective (Figure 6), similar trends can be identified, such as the nature of the main title words and their respective landscapes. However, the avoidance of deleting a large number of links allowed maintaining certain associations that disappeared in the previous figure. One main result is the increased intermingling of various themes within same clusters.

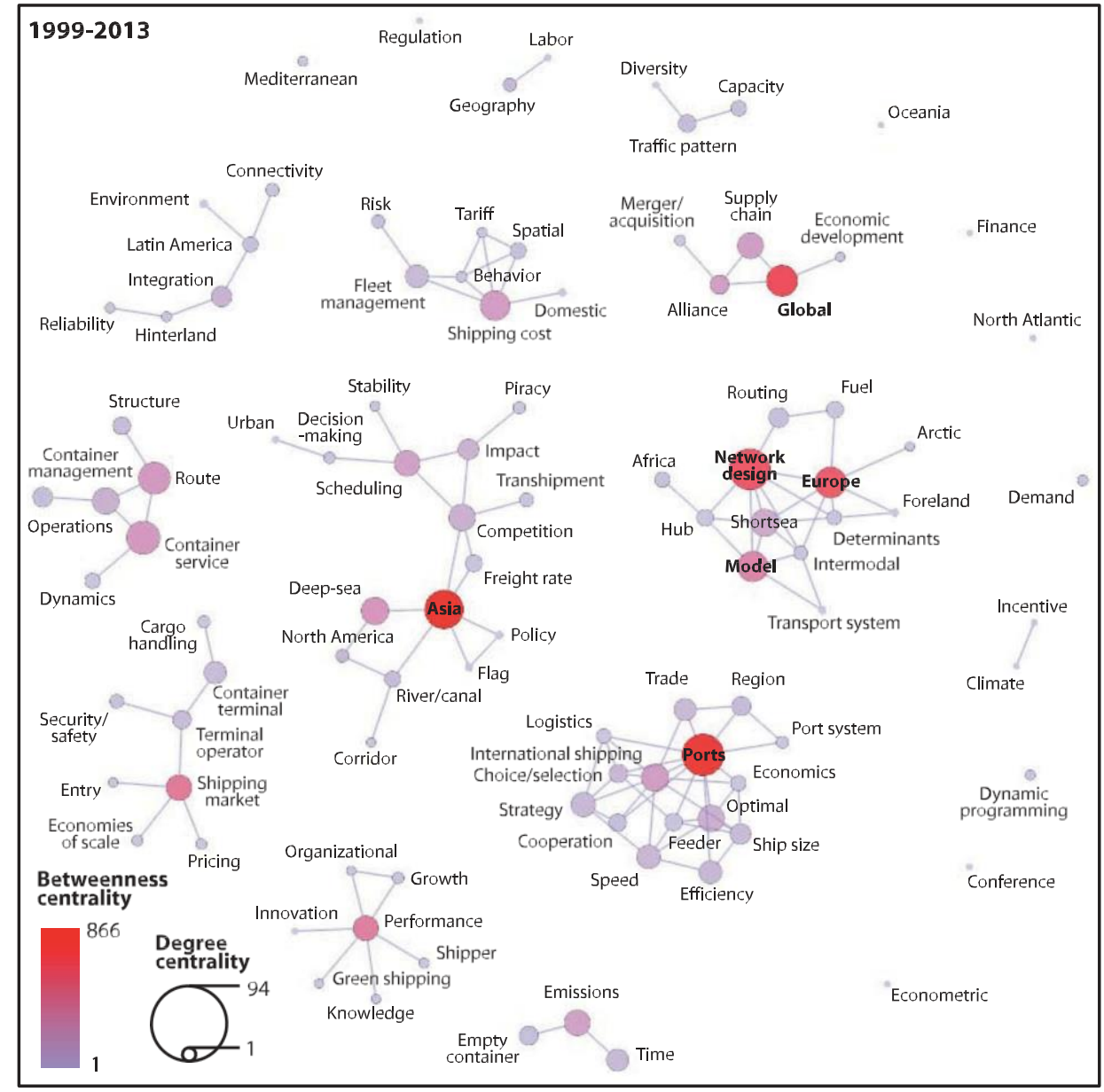

Figure 6. Bisecting k-means analysis of title words, 1999-2013.

Source: Own realization based on TULIP software. 


\section{Conclusion}

The shipping industry has been fundamentally transformed by the expansion of international trade, intermodal transport development, land and sea side integration, complex supply chain management, and technological innovation, notably containerization during the past five decades. Accordingly, this was followed by a significant increase in studies addressing different aspects of container shipping, including operations, management, and economics. Despite such availability, however, important questions have remained unanswered, notably the structure of container shipping research, and the major contributions that this community has made to the container shipping industry, global and regional economies. This paper provides content and semantic analysis on studies of container shipping between 1967 and 2013 so that the structure and evolution path of academia collaboration as well as research focuses could be identified over extended periods.

Our analysis of the container shipping literature suggests that economics, management, and operations management have become the leading research areas, although more economics studies were carried out in earlier days. Overtime, as the operations management approach increasingly applied in various disciplines, the strong linkage between economics-operation management, and to some extent the linkage between economics-management, have weakened over time. On the one hand, such a pattern reflects increased research specialization. On the other hand, this is due to the increasing awareness of analysing container shipping in a broader context of supply chain management. Indeed, port and shipping routes are increasingly studied in container shipping papers over our sample periods, a testimony that academia is looking beyond individual research constructs. The concurrent trends of specialization and diversification call for in-depth cooperation among researchers from different disciplines. However, our analysis on co-authorships suggests that the potential of cross-disciplinary investigations has yet to realize its full potential. Although there is a significant increase of collaborative works in the past 15 years following some embryonic development in the 1983-1998 period, certain 'trunk lines' have gradually been established within the research community. Moreover, the collaborative structure was not yet truly 'international' and 'external,' with collaborations being dominated by different small, enclosed 'research battalions,' mostly developed within the same department and university, or between $\mathrm{PhD}$ students/ graduates and their supervisors. These observations imply that research collaboration calls for intensive interactions in addition to improvements in communication and mobility across continents. These observations offer a mixed message: on the one hand, cooperation will 'naturally' grow over time with $\mathrm{PhD}$ graduation and researcher relocation. On the other hand, this also suggests that although conference and technological advancement have allowed the community to stay connected, they are not effective in initiating cooperation in the first place, especially for cross-disciplinary initiatives. One of the most important added values of collaboration, namely the combination of knowledge and experiences from different places and cultures, is yet to achieve its full potential. With the concurrent trend of research specialization and diversification, true inter-disciplinary studies are still limited in number and are yet to be fully developed. Our study reveals the shifting patterns of research topics and academia cooperation over time by investigating collaborative and semantic patterns in the container shipping literature. While being a highly useful tool, we recognize the potential limitations of social network analysis which might affect the power in explaining the motivations of actors (in this case, authors) and the meaning of the relations they had established (Tzatha and Schepers 2009). Our investigation does not direct to any immediate recommendation either. Instead, it simply highlights the need for some major changes to promote indepth cooperation. It is eventually up to the maritime research community to come up with innovative solutions. While risking going too far from our analysis, we note giving $\mathrm{PhD}$ students more diversified, cross-disciplined training may be a candid solution. ${ }^{4}$ Cross- 
disciplinary cooperation, either in the forms of inter-faculty centres, joint projects, or government research grants, may all help. We hope that this study offers a supporting evidence of such a trend to the maritime community so that innovative solutions could be identified in the next half-a-century. With the latest major restructuring of the shipping industry (e.g. the liquidation of Hanjin Shipping, the merging of China Shipping, and COSCO into China COSCO Shipping Corporation) and the political development (e.g. the prospect of Brexit), we believe that this study can offer a very interesting platform for further research in this area.

Although the methods used in this study are well established, there are some limitations in data analysis. For a comprehensive review, 294 papers published in 31 journals have been included in our analysis. Apparently, these papers and journals are of different quality and influence. It would be useful to control such effects in our analysis. One possible approach is to incorporate each paper's citations with different weights on each publication. Also, it would be useful to include the keywords or even abstract of an article when such information can be compiled and analysed and even extend the analysis to the whole body of the articles to perform big data analyses on evolving semantics and research trends. As the study sample in this paper only included journal articles, seminal books or other forms of publication might constitute some 'missing links' in our analysis. Other research pathways include the extension of this analysis to the entire shipping research corpus, including other maritime sectors than sole container shipping, such as bulks and passengers. One possibility would be to run, for instance, a similar analysis based on the contributions to international conferences such as those organized for decades by the International Association of Maritime Economists and the World Conference on Transport Research Society. These extensions are likely to enrich our analysis and lead to fresh insights, albeit beyond the scope that the current paper aims to achieve.

\section{Notes}

1. http://tulip.labri.fr/TulipDrupal/.

2. The categorization reflects the research topics and discipline classifications as identified in Lau et al. (2013). It is possible to include more subcategories in the analysis. However, this may not necessarily generate more insights as the definition of more numerous semantic areas often leads to complex patterns that are difficult to interpret.

3. We have calculated that the average number of characters increased over the periods from 57 to 70 and 77 , which is a good indicator of the growth in length of article titles, all words included. However, considering only the selected words, it has increased more smoothly from 27 to 28 and 35 on average. The average number of selected words has grown from 2.54 to 2.65 and 3.28. This is not a new trend, as already in the 1970s, scholars observed the increase in the number of substantive title words in many scientific fields and across different languages (Buxton and Meadows 1977). However, this tends to complicate the analysis of co-occurrences due to the equivalent increase in the number of words, expressions, and links between them.

4. We note that in the University of California at Berkeley, $\mathrm{PhD}$ students in the civil engineering program are allowed to pursue Master's Degree in economics and finance. In many other universities, business schools recruit research students with backgrounds in engineering and mathematics.

\section{Acknowledgements}

This study has received funding from the European Research Council under the European Union's Seventh Framework Programme [(FP/2007-2013)/ERC Grant Agreement Number 313847] 'World Seastems' and the Transport Institute of the University of Manitoba.

\section{Disclosure statement}

No potential conflict of interest was reported by the authors. 


\section{Funding}

This study has received funding from the European Research Council under the European Union's Seventh Framework Programme [(FP/2007-2013)/ERC Grant Agreement Number 313847] 'World Seastems' and the Transport Institute of the University of Manitoba.

\section{ORCID}

César Ducruet (iD) http://orcid.org/0000-0002-0946-4712

\section{References}

Berger, P. L., and T. Luckmann. 1966. The Social Construction of Reality: A Treatise in the Sociology of Knowledge. Garden City, NY: Anchor Books.

Buxton, A. B., and A. J. Meadows. 1977. "The Variation in the Information Content of Titles of Research Papers with Time and Discipline." Journal of Documentation 33 (1): 46-52. doi:10.1108/eb026633.

Containerisation International Yearbook. 2016. Containerisation International. London.

de Bakker, F. G. A., P. Groenewegen, and F. Den Hond. 2005. "A Bibliometric Analysis of 30 Years of Research and Theory on Corporate Social Responsibility and Corporate Social Performance." Business and Society 44 (3): $283-$ 317. doi:10.1177/0007650305278086.

De Langen, P. W. 2007. "Stakeholders, Conflicting Interests and Governance in Port Clusters." Research in Transportation Economics 17: 457-477. doi:10.1016/S0739-8859(06)17020-1.

Du, Y., Q. Meng, and S. Wang. 2017. "Mathematically Calculating the Transit Time of Cargo through a Liner Shipping Network with Various Trans-Shipment Policies." Maritime Policy \& Management 44 (2): 248-270. doi:10.1080/03088839.2016.1274831.

Ducruet, C., ed. 2015. Maritime Networks. Spatial Structures and Time Dynamics. London: Routledge Studies in Transport Analysis.

Ducruet, C. 2017. "Multilayer Dynamics of Complex Spatial Networks: The Case of Global Maritime Flows (19772008)." Journal of Transport Geography 60: 47-58. doi:10.1016/j.jtrangeo.2017.02.007.

Ducruet, C., and I. Lugo. 2013. "Cities and Transport Networks in Shipping and Logistics Research." Asian Journal of Shipping and Logistics 29 (2): 149-170. doi:10.1016/j.ajsl.2013.08.002.

Ferrari, C., F. Parola, and E. Gattorna. 2011. "Measuring the Quality of Port Hinterland Accessibility: The Ligurian Case." Transport Policy 18 (2): 382-391. doi:10.1016/j.tranpol.2010.11.002.

Ferrer, R., I. Cancho, and R. V. Sole. 2001. "The Small World of Human Language." Proceedings of the Royal Society B: Biological Sciences 268 (1482): 2261-2265. doi:10.1098/rspb.2001.1800.

Granovetter, M. S. 1973. "The Strength of Weak Ties." The American Journal of Sociology 78: 1360-1380. doi:10.1086/225469.

Guerrero, D., and J. P. Rodrigue. 2014. "The Waves of Containerization: Shifts in Global Maritime Transportation." Journal of Transport Geography 35: 151-164. doi:10.1016/j.jtrangeo.2013.12.003.

Homsombat, W., A. K. Y. Ng, and X. Fu. 2016. "Regional Transformation and Port Cluster Competition: The Case of the Pearl River Delta in South China." Growth and Change 47 (3): 349-362. doi:10.1111/grow.12128.

Homsombat, W., T. L. Yip, H. Yang, and X. Fu. 2013. "Regional Cooperation and Management of Port Pollution." Maritime Policy \& Management 40 (5): 451-466. doi:10.1080/03088839.2013.797118.

IMO (International Maritime Organisation). 2000. "Prevention of Air Pollution from Ships, Consideration of an IMO Strategy for Greenhouse Gases Reduction." MEPC 45/8/3, New York.

IMO (International Maritime Organization). 2009. Interim Guidelines on the Method of Calculation of the Energy Efficiency Design Index for New Ships. MEPC.1/Circ.681, London: IMO.

Jacques, T. S., and N. J. Sebire. 2010. "The Impact of Article Titles on Citation Hits: An Analysis of General and Specialist Medical Journals." Journal of the Royal Society of Medicine. 1 (1): 2. doi: 10.1258/shorts.2009.100020. Open Access.

Knuth, D. E. 1993. The Stanford Graphbase: A Platform for Combinatorial Computing. New York, NY: ACM. Lam,

J., A. K. Y. Ng, and X. Fu. 2013. "Stakeholder Management for Establishing Sustainable Regional Port Governance." Research in Transportation Business \& Management 8: 30-38. doi:10.1016/j.rtbm.2013.06.001.

Lau, Y. Y., A. K. Y. Ng, X. Fu, and K. X. Li. 2013. "Evolution and Research Trends of Container Shipping." Maritime Policy \& Management 40 (7): 654-674. doi:10.1080/03088839.2013.851459.

Lewison, G., and J. Hartley. 2005. "What's in a Title? Numbers of Words and the Presence of Colons." Scientometrics 63 (2): 341-356. doi:10.1007/s11192-005-0216-0. 
Milojević, S., C. R. Sugimoto, E. Yan, and Y. Ding. 2011. "The Cognitive Structure of Library and Information Science: Analysis of Article Title Words." Journal of the Association for Information Science and Technology 62 (10): 1933-1953. doi:10.1002/asi.21602.

Newman, M. E. J. 2004. "Co-Authorship Networks and Patterns of Scientific Collaboration." Proceedings of the National Academy of Sciences of the United States of America 101: 5200-5205. doi:10.1073/pnas.0307545100.

Newman, M. E. J. 2010. Networks: An Introduction. Oxford: Oxford University Press.

Ng, A. K. Y. 2006. "Assessing the Attractiveness of Ports in the North European Container Transhipment Market: An Agenda for Future Research in Port Competition." Maritime Economics \& Logistics 8 (3): 234-250. doi:10.1057/palgrave.mel.9100158.

Ng, A. K. Y. 2013. "The Evolution and Research Trends of Port Geography.” The Professional Geographer 65 (1): 65-86. doi:10.1080/00330124.2012.679441.

Ng, A. K. Y., and C. Ducruet. 2014. "The Changing Tides of Port Geography (1950-2012)." Progress in Human Geography 38 (6): 785-823. doi:10.1177/0309132513516178.

Ng, A. K. Y., C. Ducruet, W. Jacobs, J. Monios, T. E. Notteboom, J. P. Rodrigue, B. Slack, K. C. Tam, and G. Wilmsmeier. 2014. "Port Geography at the Crossroads with Human Geography: Between Flows and Spaces." Journal of Transport Geography 41: 84-96. doi:10.1016/j.jtrangeo.2014.08.012.

Ng, A. K. Y., and J. J. Liu. 2014. Port-Focal Logistics and Global Supply Chains. Basingstoke: Palgrave Macmillan.

Notteboom, T. E. 2009. "The Relationship between Seaports and the Intermodal Hinterland in Light of Global Supply Chains: European Challenges." OECD, International Transport Forum, Round Table 143.

Notteboom, T. E., A. A. Pallis, P. W. De Langen, and A. Papachristou. 2013. "Advances in Port Studies: The Contribution of 40 Years Maritime Policy \& Management." Maritime Policy \& Management 40 (7): 636-653. doi:10.1080/03088839.2013.851455.

Nystuen, J. D., and M. F. Dacey. 1961. "A Graph Theory Interpretation of Nodal Regions." Papers in Regional Science 7 (1): 29-42. doi:10.1007/BF01969070.

Pallis, A. A., T. K. Vitsounis, P. W. De Langen, and T. E. Notteboom. 2011. "Port Economics, Policy and Management - Content Classification and Survey." Transport Reviews 31 (4): 445-471. doi:10.1080/ 01441647.2010.530699.

Pan, R. K., K. Kaski, and S. Fortunato. 2012. "World Citation and Collaboration Networks: Uncovering the Role of Geography in Science." Scientific Reports 2: 1-7. article number: 902. doi:10.1038/srep00902.

Pelletier, J. F., and Y. Alix. 2004. "Vers Une Nouvelle Approche Méthodologique Pour Analyser Le Phénomène De La Conteneurisation Des Marchandises Au Canada." Proceedings of the 39th GRTC Annual Conference 1:326-341.

Psaraftis, H., and C. Kontovas. 2009. "CO2 Emission Statistics for the World Commercial Fleet." WMU Journal of Maritime Affairs 8: 1-25. doi:10.1007/BF03195150.

RGS-IBG. 2014. "Between Path Dependency and Contingency: New Challenges for the Geography of Port System Evolution." Sessions (chaired by Wilmsmeier and Monios) organized during the Annual Conference of the Royal Geographical Society (in collaboration with the Institute of British Geographers) (RGS-IBG), London, UK, 29 August 2014, http://conference.rgs.org/Conference/Sessions/SimpleSearchDay.aspx? conference= AC2014\&date $=2014-08-29$.

Robinson, R. 2002. "Ports as Elements in Value-Driven Chain Systems: The New Paradigm." Maritime Policy \& Management 29 (3): 241-255. doi:10.1080/03088830210132623.

Savaresi, S. M., and D. L. Boley. 2004. "A Comparative Analysis on the Bisecting K-Means and the PDDP Clustering Algorithms." Intelligent Data Analysis 8 (4): 345-362.

Shi, W., and K. X. Li. 2017. "Themes and Tools of Maritime Transport Research during 2000-2014." Maritime Policy \& Management 44 (2): 151-169. doi:10.1080/03088839.2016.1274833.

Slack, B., and A. Fremont. 2005. "Transformation of Port Terminal Operations: From the Local to the Global." Transport Reviews 25 (1): 117-130. doi:10.1080/0144164042000206051.

Talley, W. 2013. "Maritime Transportation Research: Topics and Methodologies." Maritime Policy \& Management 40 (7): 709-725. doi:10.1080/03088839.2013.851463.

Tzatha, A., and J. Schepers. 2009. "The Limitations of Social Network Analysis." Journal of Network Theory 2: 4.

UNCTAD. 2014. Review of Maritime Transport. Geneva: United Nations Conference on Trade and Development.

UNCTAD. 2015. Review of Maritime Transport. Geneva: United Nations Conference on Trade and Development.

Wang, J. J. 1998. "A Container Load Center with A Developing Hinterland: A Case Study of Hong Kong." Journal of Transport Geography 6 (3): 187-201. doi:10.1016/S0966-6923(98)00011-8.

Wang, K., X. Fu, and M. Luo. 2015. "Modeling the Impacts of Alternative Emission Trading Schemes on International Shipping." Transportation Research Part A: Policy and Practice 77: 35-49.

Wilson, W., ed. 2013. "A Symposium Commemorating 40 Years of Maritime Research, Special Issue Published In". Maritime Policy \& Management 40 (7): 615-725. doi;10.1080/03088839.2013.851453.

Woo, S. H., S. J. Pettit, D. W. Kwak, and A. K. C. Beresford. 2011. "Seaport Research: A Structured Literature Review on Methodological Issues since the 1980s." Transportation Research Part A: Policy and Practice 45 (7): $667-685$.

Zaidi, F. 2011. Analysis, Structure and Organization of Complex Networks. Saarbrücken: LAP. 


\section{Appendix 1. Top 20 frequencies of title words and expressions by period}

\begin{tabular}{lrllll}
\hline \multicolumn{1}{c}{ 1967-1982 } & & \multicolumn{1}{c}{ 1983-1998 } & & 1999-2013 \\
\hline North America & 12 & Competition & 11 & Ports & 97 \\
Freight rate & 9 & Shipping market & 11 & Network design & 84 \\
Container service & 7 & Deep-sea & 10 & Asia & 76 \\
Pricing & 7 & Developing countries & 8 & Europe & 55 \\
Route & 7 & Europe & 8 & Container service & 54 \\
Time & 6 & Optimal & 8 & Container management & 50 \\
Trade & 6 & Model & 7 & Global & 48 \\
Cooperation & 5 & Conference & 6 & Optimal & 46 \\
Optimal & 5 & Global & 6 & Model & 45 \\
Shipping cost & 5 & Hinterland & 6 & Competition & 43 \\
Economics & 4 & Impact & 6 & Shipping cost & 42 \\
Europe & 4 & Trade & 6 & Short-sea & 42 \\
Asia & 3 & Contract & 5 & Emissions & 41 \\
Conference & 3 & Economies of scale & 5 & Route & 41 \\
Deep-sea & 3 & Geography & 5 & Deep-sea & 40 \\
Demand & 3 & North America & 5 & International shipping & 40 \\
Econometric & 3 & Shipper & 5 & Scheduling & 38 \\
Fuel & 3 & Shipping cost & 5 & Fleet management & 37 \\
Impact & 3 & Spatial & 5 & Speed & 36 \\
International shipping & 3 & Traffic pattern & 5 & Supply chain & 35 \\
\hline
\end{tabular}

\section{Appendix 2. Journal papers analysed in addition to the database compiled in Lau}

et al. (2013)

Asgari, N., Farahani, R.Z. and Goh, M. (2013), Network design approach for hub ports-shipping companies competition and cooperation, Transportation Research Part A, 48, 1-18.

Kim, J.G., Kim, H.J. and Lee, P.T.W. (2013), Optimising containership speed and fleet size under a carbon tax and an emission trading scheme, International Journal of Shipping and Transport Logistics, 5(6), 571-590.

Lai, K.H., Lun, Y.H.V., Wong, C.W.Y. and Cheng, T.CE. (2013), Measures for evaluating green shipping practices implementation, International Journal of Shipping and Transport Logistics, 5(2), 217-235.

Lam, J.S.L. (2013), Towards a normative model for managing container shipping supply chains, International Journal of Logistics Systems and Management, 14(2), 200-220.

Lam, J.S.L. (2013), Benefits and barriers of supply chain integration: empirical analysis of liner shipping, International Journal of Shipping and Transport Logistics, 5(1), 13-30.

Lau, Y.Y., Ng, A.K.Y., Fu, X. and Li, K.X. (2013), Evolution and research trends of container shipping, Maritime Policy \& Management, 40(7), 654-674.

Lee, T.C., Chang, Y.T. and Lee, P.T.W. (2013), Economy-wide impact analysis of a carbon tax on international container shipping, Transportation Research Part A, 58, 87-102.

Lu, C.S., Kuo, S.Y. and Chiu, Y.T. (2013), Ethical leadership and ethical climate in the container shipping industry, International Journal of Shipping and Transport Logistics, 5(6), 591-604.

Pristrom, S., Li, K.X., Yang, Z. and Wang J. (2013), A study of maritime security and piracy, Maritime Policy \& Management, 40(7), 675-693.

Seoane, M.J.F., Laxe, F.G. and Montes, C.P. (2013), Foreland determination for containership and general cargo ports in Europe (2007-2011), Journal of Transport Geography, 30, 56-67.

Talley, W.K. (2013), Maritime transportation research: Topics and methodologies, Maritime Policy \& Management, 40(7), 709-725.

Wiegmans, B., Bu, L. and Kim, N.S. (2013), Deep-sea container carrier performance: how efficient are the respective container carriers? International Journal of Shipping and Transport Logistics, 5(1), 55-74.

Remarks: for the details of the 282 papers published on or before 2012, see Lau et al. (2013). 